\title{
Identification of the Streptococcus mutans LytST two-component regulon reveals its contribution to oxidative stress tolerance
}

\author{
Sang-Joon Ahn ${ }^{1}$, Ming-Da Qu², Elisha Roberts ${ }^{2}$, Robert A Burne ${ }^{1}$ and Kelly C Rice ${ }^{2^{*}}$
}

\begin{abstract}
Background: The S. mutans LrgA/B holin-like proteins have been shown to affect biofilm formation and oxidative stress tolerance, and are regulated by oxygenation, glucose levels, and by the LytST two-component system. In this study, we sought to determine if LytST was involved in regulating $\operatorname{lrg} A B$ expression in response to glucose and oxygenation in S. mutans.

Results: Real-time PCR revealed that growth phase-dependent regulation of $\operatorname{Irg} A B$ expression in response to glucose metabolism is mediated by LytST under low-oxygen conditions. However, the effect of LytST on IrgAB expression was less pronounced when cells were grown with aeration. RNA expression profiles in the wild-type and lyts mutant strains were compared using microarrays in early exponential and late exponential phase cells. The expression of 40 and 136 genes in early-exponential and late exponential phase, respectively, was altered in the lyts mutant. Although expression of $c 0 m Y B$, encoding a DNA binding-uptake protein, was substantially increased in the lytS mutant, this did not translate to an effect on competence. However, a $\operatorname{Irg} A$ mutant displayed a substantial decrease in transformation efficiency, suggestive of a previously-unknown link between LrgA and S. mutans competence development. Finally, increased expression of genes encoding antioxidant and DNA recombination/ repair enzymes was observed in the lytS mutant, suggesting that the mutant may be subjected to increased oxidative stress during normal growth. Although the intracellular levels of reaction oxygen species (ROS) appeared similar between wild-type and lytS mutant strains after overnight growth, challenge of these strains with hydrogen peroxide $\left(\mathrm{H}_{2} \mathrm{O}_{2}\right)$ resulted in increased intracellular ROS in the lyts mutant.

Conclusions: Overall, these results: (1) Reinforce the importance of LytST in governing IrgAB expression in response to glucose and oxygen, (2) Define a new role for LytST in global gene regulation and resistance to $\mathrm{H}_{2} \mathrm{O}_{2}$, and (3) Uncover a potential link between LrgAB and competence development in S. mutans.
\end{abstract}

Keywords: Stress, Oxygen, Competence, Cid/Lrg system, Streptococcus mutans

\section{Background}

Streptococcus mutans is considered the primary causative agent of dental caries, and when transiently introduced into the bloodstream following daily dental hygienic practices such as toothbrushing and flossing, this bacterium can also cause potentially lethal infective endocarditis (IE) [1-4]. In both infectious scenarios, the virulence of $S$. mutans depends upon its ability to form biofilms and to withstand extreme changes in

\footnotetext{
*Correspondence: kcrice@ufl.edu

${ }^{2}$ Department of Microbiology and Cell Science, College of Agricultural and

Life Sciences, University of Florida, Gainesville, FL 32611, USA

Full list of author information is available at the end of the article
}

environmental conditions, including fluctuations in oxygenation, shear stress, as well as nutrient source and availability. For example, in the oral cavity, S. mutans must be able to rapidly alter its expression of transporters and metabolic enzymes to catabolize a variety of host-derived dietary carbohydrates. Internalized carbohydrates are metabolized through the glycolytic pathway, resulting in the accumulation of acidic end-products in the environment, which favors the growth of S. mutans and other acid-tolerant cariogenic species. Repeated cycles of acidification can lead to a net demineralization of tooth enamel and the development of caries. Sucrose, a common dietary sweetener, can also be utilized by

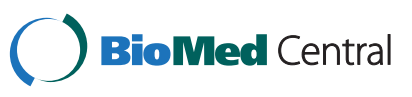


S. mutans for the production of extracellular polysaccharides [5-8] that facilitate bacterial adhesion and biofilm formation. Aeration has also been found to have a profound effect on carbohydrate metabolism and biofilm formation by $S$. mutans [9-11]. It is therefore not surprising that there is overlap in the genetic regulatory circuits responsive to carbohydrate metabolism, aeration/ oxidative stress resistance and control of biofilm formation in S. mutans, which include CcpA [12-14], Rex [15], and Frp [16].

More recently, an emerging trend in the study of bacterial biofilms has been a focus on the contribution of bacterial cell death and autolysis to biofilm adherence, maturation, and dispersal. It has been demonstrated in a wide variety of bacteria that death and lysis of a subpopulation of cells can facilitate biofilm formation due to the release of DNA into the extracellular environment (eDNA) [17-22]. Likewise, cell death and lysis have been implicated in dispersal of cells from a mature biofilm [23-25]. In Staphylococcus aureus, the Cid/Lrg system has been shown to be involved in the regulation of cell death, autolysis, and biofilm formation [17,21,26-28]. Characterization of $S$. aureus cid and $l \mathrm{rg}$ mutants has revealed that these operons have opposing effects on cell death and murein hydrolase activity [27,29]. These observations, combined with the fact that LrgA and CidA share structural features with the bacteriophage lambda family of holin proteins [29], have led to the hypothesis that CidA and LrgA control cell death and lysis in a manner analogous to effector and inhibitor holins, respectively $[26,30]$. Bacteriophage holins are small membrane proteins that oligomerize in the cell membrane, acting as "molecular clocks" that regulate the timing and lysis of the host cell during lytic infection [31]. For example, the lambda $\mathrm{S}$ holin regulates cell death and lysis by the formation of large lipid-excluding "rafts" that promote cytosolic leakage as well as access of the phageencoded endolysin (murein hydrolase) to the cell wall [32-34]. S. aureus CidA and LrgA have recently been shown to oligomerize into high-molecular-mass complexes in a cysteine disulfide bond-dependent manner, a biochemical feature also shared with holin proteins [35]. Although the molecular details of how Cid and Lrg function to control cell death and lysis have not yet been completely elucidated, the fact that cid and lrg homologues have been identified in a wide variety of bacterial and archeal genomes supports a fundamental and conserved role for this system in cell physiology $[30,36]$.

In previous work it was determined that expression of potential $\operatorname{cid} A B$ and $\operatorname{lrg} A B$ homologues in $S$. mutans is highly responsive to carbohydrate availability [12,37] and oxygenation [11]. Given the potential importance of these genes to biofilm development in S. mutans, we previously characterized a panel of $S$. mutans cid and $l r g$ isogenic mutants and found that a subset of these genes did indeed influence biofilm formation, production of glucosyltransferases (enzymes that synthesize extracellular glucan polymers that contribute to biofilm adhesion), and oxidative stress tolerance [37]. In this study it was also found that, as demonstrated previously in $S$. aureus $[38,39]$, the $S$. mutans LytST two-component system was required for activation of $\operatorname{lrg} A B$ expression, but not $\operatorname{cid} A B$ expression [37]. Genes homologous to lytST appear to be present in most Gram-positive organisms that contain $\operatorname{lrg} A B$ [30] and these genes are often linked to one another, inferring an important role for this twocomponent system in fine-tuning $\operatorname{lrg} A B$ expression in response to external environmental signals. Therefore in this study, we sought to determine if LytST is involved in regulation of $\operatorname{lrg} A B$ expression in response to glucose and oxygenation in $S$. mutans, and to elaborate on the contribution of LytST to cellular homeostasis and global control of gene expression.

\section{Results}

\section{Effects of oxygenation and glucose metabolism on S. mutans Irg and cid expression}

The LytST two-component regulatory system has been shown to positively regulate $\operatorname{lrg} A B$ expression in a wide variety of bacteria, including various staphylococcal [38-40] and Bacillus species [41,42], as well as in S. mutans [37]. The conserved nature of this regulation in Gram-positive bacteria, combined with the known effects of LytST and LrgAB on cell death/lysis [29,38,39,43], biofilm development $[21,37,38]$, and oxidative stress resistance [37], suggests that LytST and LrgAB are central regulators of physiologic homeostasis. However, little is known about the environmental and/or cellular cues to which LytS responds. In $S$. aureus and B. anthracis, it has been shown that $\operatorname{lrg} A B$ expression is responsive to disruption of cell membrane potential in a LytST-dependent manner $[41,44]$. However, we were unable to determine whether this regulation also occurs in S. mutans, as treatment with membrane-potential disrupting agents (gramicidin, carbonyl cyanide m-chlorophenylhydrazone) did not have a measurable effect on membrane potential, as assessed by staining with $\mathrm{DIOC}_{2}$ (3) (data not shown).

In previous studies, it was shown that oxygen and glucose metabolism have a pronounced effect on $l r g$ and cid expression in S. mutans, but the specific role of LytS, if any, in this regulation was not addressed [11,37]. Therefore, S. mutans UA159 and its isogenic lytS mutant were grown under aerobic and low-oxygen conditions to exponential (EP) and stationary (SP) growth phases in media containing $11 \mathrm{mM}$ or $45 \mathrm{mM}$ glucose. Quantitative real-time reverse transcriptase PCR (qRT-PCR) was performed on RNA isolated from cultures at each time 
point to assess changes in $\operatorname{lrg}$ expression (Figure 1). In UA159, stationary phase $\operatorname{lrg} A B$ expression was upregulated 365-fold relative to exponential phase when grown under $11 \mathrm{mM}$ glucose and low-oxygen conditions (Figure 1A). Although mutation of lytS resulted in a severe loss of stationary phase $\operatorname{lrg} A B$ induction in cells grown in $11 \mathrm{mM}$ glucose, $\operatorname{lrg} A B$ expression was not completely abolished. When grown under aerobic conditions and $11 \mathrm{mM}$ glucose, stationary phase $\operatorname{lrg} A B$ expression was upregulated 2500 -fold relative to exponential phase in the wild-type strain (Figure 1A), confirming previously-published observations that aerobic growth promotes $\operatorname{lrg} A B$ expression [11]. However, stationaryphase $\operatorname{lrg} A B$ expression was still induced 216-fold in the lytS mutant during aerobic growth, suggesting that (1) other as-yet-unknown regulators also contribute to the positive control of $\operatorname{lrg} A B$ expression during aerated growth, and (2) LytST is a predominant regulator of $\operatorname{lrg} A B$ expression during low oxygen growth, compared to aerobic growth. Under low-oxygen and aerated cultures, stationary phase induction of $\operatorname{lrg} A B$ expression was dramatically reduced when grown in $45 \mathrm{mM}$ glucose, and similar levels of expression were observed in the wild-type and lytS mutant (Figure 1B), suggesting that growth in high levels of glucose abrogates oxygendependent regulation of $\operatorname{lrg} A B$ by LytST. Consistent with previously-published data [37], LytS did not appear to have a measurable effect on $\operatorname{cid} A B$ expression under any of the growth conditions tested here (data not shown). In summary, LytST-dependent regulation of $\operatorname{lrg} A B$ expression is much more pronounced during low-oxygen growth and at low glucose levels.

\section{Microarray analysis of the LytS regulon}

Based on the transcriptional data presented above, the effects of LytST regulation on $\operatorname{lrg} A B$ expression are most evident while $S$. mutans is growing under conditions of low-oxygen $\left(5 \% \mathrm{CO}_{2}\right)$ with a lower concentration of glucose. To begin to explore how LytST impacts critical phenotypes of S. mutans, RNA expression profiles in UA159 and the lytS mutant were compared using an RNA microarray approach. RNA was isolated from early exponential and late exponential growth phases from static planktonic cultures grown in $\mathrm{BHI}$ (containing $11 \mathrm{mM}$ total glucose) at $37^{\circ} \mathrm{C}$ in a $5 \% \mathrm{CO}_{2}$ atmosphere (Additional file 1: Table S1 and Additional file 2: Table S2). At early exponential growth phase, loss of LytS affected the expression of 40 genes (12 upregulated and 28 downregulated; $P<0.005$; Additional file 1: Table S1). Most of the upregulated genes in early exponential phase displayed only a modest increase in expression and included genes involved in DNA repair, purine/ pyrimidine metabolism, competence, and a number of unassigned and hypothetical ORFs. RNA transcripts that were strongly down-regulated greater than 10-fold in cells lacking LytS during early exponential growth included those annotated as bacitracin/surfactin/gramicidin synthesis proteins, transport and binding proteins, and LrgAB. In contrast, loss of LytS affected the expression of a much larger number of genes in late exponential phase (136 genes total), with 79 upregulated transcripts and 57 downregulated transcripts $(P<0.001$; Additional file 2: Table S2). Aside from dramatically decreased $\operatorname{lrg} A B$ expression, affected genes included those involved in amino acid and co-factor biosynthesis, carbohydrate and fatty acid metabolism, stress adaptation, toxin production, DNA repair/recombination,
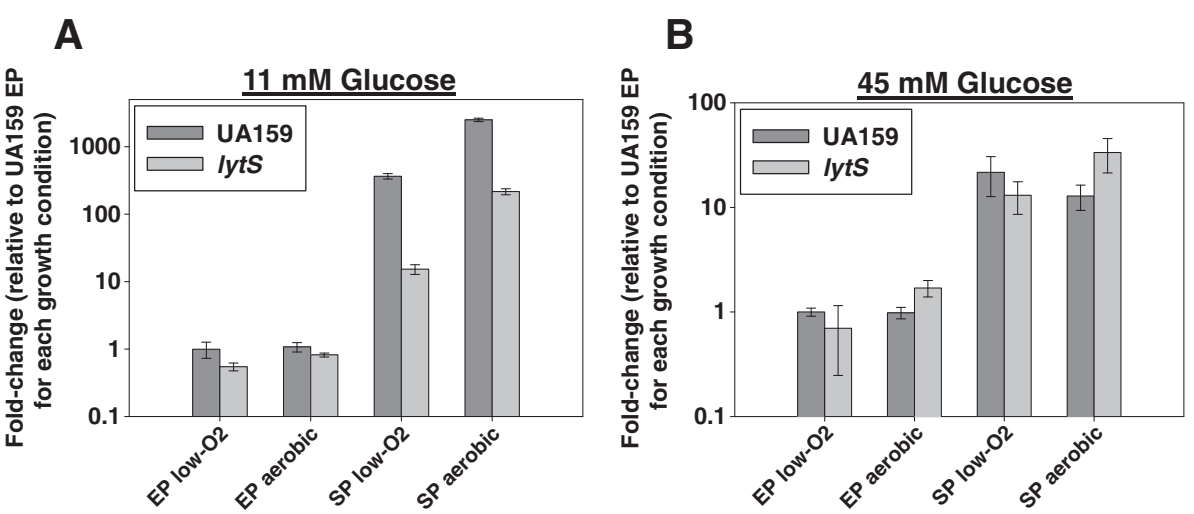

Figure 1 LytS-dependent expression of IrgAB in S. mutans. Overnight cultures were diluted in THYE, containing either $11 \mathrm{mM}(\mathbf{A})$ or $45 \mathrm{mM}$ glucose (B) to an $\mathrm{OD}_{600}=0.02$ and grown at $37^{\circ} \mathrm{C}$ as static cultures at $5 \% \mathrm{CO}_{2}$ ("low- $\mathrm{O}_{2}$ ") or as aerobic shaking cultures at 250 RPM ("aerobic"). RNA was harvested at exponential (EP) and stationary phase (SP). Reverse-transcription, real-time PCR reactions, and determination of copy number were performed as described previously using IrgA and 16S-specific primers [37,77]. Fold-change expression of IrgAB and 165 under each growth condition was calculated by dividing the gene copy number of each test sample by the average gene copy number of UA159 EP. Data was then normalized by dividing each IrgAB fold-change value by its corresponding 165 fold-change expression value. Data represent the average of 3 biological replicates. Dark grey bars represent UA159 and light grey bars represent lytS mutant. Error Bars represent the standard error (SEM). 
protein synthesis, transcriptional regulation, and competence, as well as multiple hypothetical and/or unassigned ORFs (Additional file 2: Table S2 and Figure 2). A subset of genes was differentially expressed as a function of the loss of LytS in both early exponential and late exponential growth phases (Additional file 1: Table S1 and Additional file 2: Table S2). These included many genes encoded by the S. mutans genomic island TnSMu2 [45] (SMU.1335c, 1339-1342, 1344c-1346, 1354c, 1360c, 1363c, 1366c), ssbA, $\operatorname{com} Y B$, and $\operatorname{lrg} A B$. Given that these genes were regulated by LytS in both growth phases examined, it is possible that they are under the direct control of LytST. To validate the microarray data, qRT-PCR was performed on late exponential phase wild-type and lytS mutant RNA to assess expression of 14 of the affected genes. As shown in Table 1, the expression ratios (lytS mutant/wild-type) for each gene obtained by real-time PCR were similar to the microarray results. Interestingly, expression ratios of these genes were all close to 1.0 when comparing expression between the wild-type strain and a $\operatorname{lrg} A B$ mutant (Table 1), indicating that the differential expression patterns observed in the lytS
Table 1 Real-time PCR validation of RNA microarray results

\begin{tabular}{|c|c|c|c|c|}
\hline & \multirow{2}{*}{$\frac{\text { Microarray }}{\text { lytS mutant }}$} & \multicolumn{2}{|c|}{ Real-time pcr } \\
\hline & & & lyts mutant & $\operatorname{Irg} A B$ mutant \\
\hline (SMU.1985) & comYA (comYB) & 22.9927 & 6.8449 & 0.8163 \\
\hline SMU.1967 & $s s b A$ & 5.5803 & 4.1076 & 0.8791 \\
\hline (SMU.1515) & $\operatorname{vicR}(\operatorname{vic} X)$ & 2.6764 & 1.7647 & 1.0267 \\
\hline SMU.924 & $t p x$ & 2.4148 & 3.6168 & 1.058 \\
\hline SMU.1739 & $f a b F$ & 2.2443 & 2.0333 & 1.084 \\
\hline SMU.1666 & livG & 2.1183 & 3.4331 & 1.009 \\
\hline SMU.80 & $\operatorname{hrcA}$ & 0.4953 & 0.6107 & 1.0204 \\
\hline SMU.1424 & $p d h D$ & 0.4769 & 0.4031 & 1.2004 \\
\hline SMU.580 & xseA & 0.29849 & 0.5409 & 1.1398 \\
\hline SMU.1600 & $c e l B$ & 0.2186 & 0.2825 & 1.2979 \\
\hline SMU.113 & $p f k$ & 0.1597 & 0.176 & 1.3578 \\
\hline SMU.82 & dnak & 0.1523 & 0.2652 & 0.9907 \\
\hline SMU.1344 & $f a b D$ & 0.0223 & 0.012 & 1.0637 \\
\hline SMU.1341 & grs & 0.0008 & 0.0121 & 1.1027 \\
\hline
\end{tabular}

Results are expressed in fold-change (mutant/wild-type).

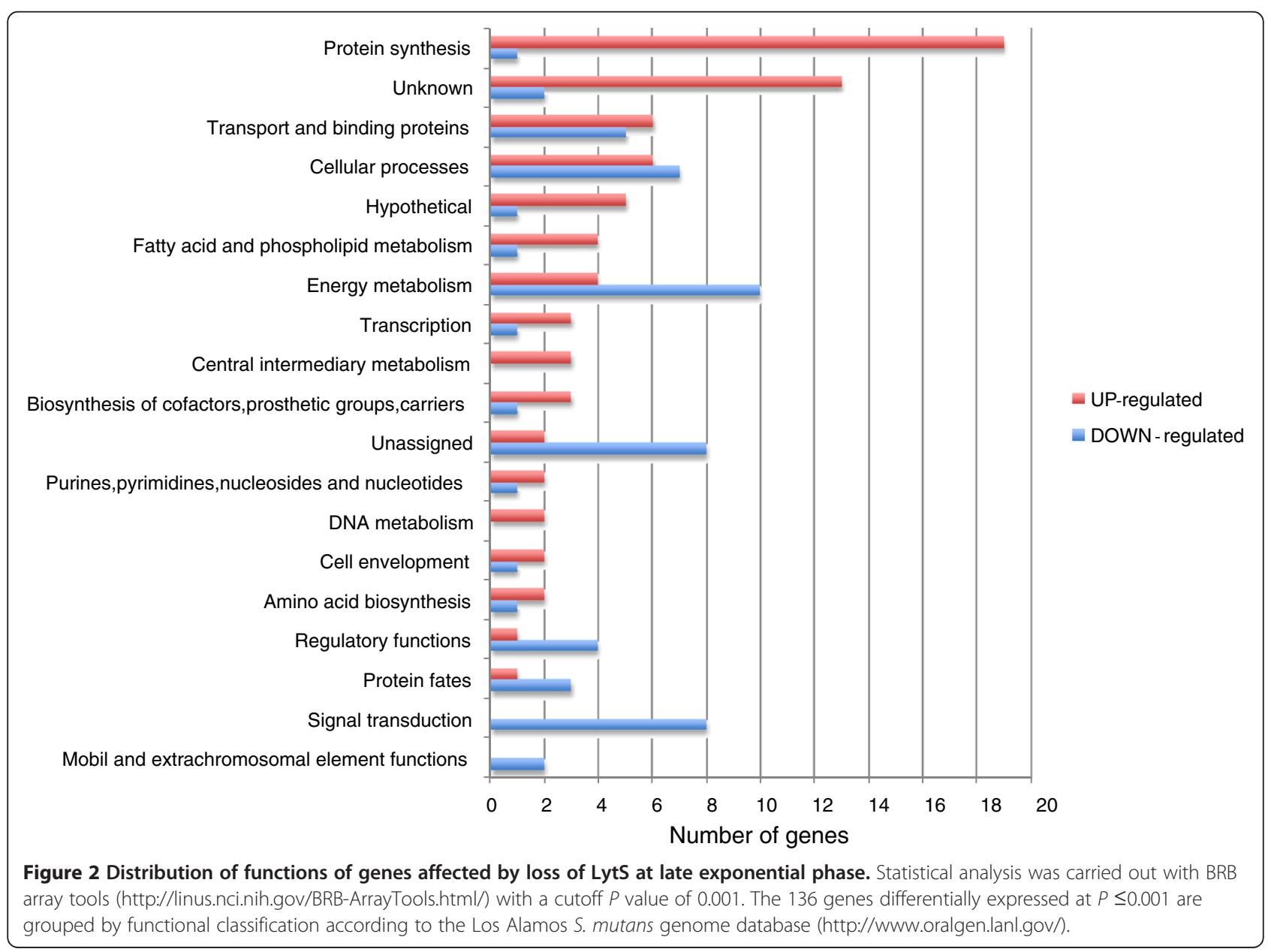


mutant were not a consequence of down-regulated $\operatorname{lrg} A B$ expression.

\section{Investigation of the effect of LytST and LrgAB on competence}

In analyzing the microarray data in Additional file 1: Table S1 and Additional file 2: Table S2, it appeared that the gene most highly upregulated in response to loss of LytS in both phases of growth was $\operatorname{com} Y B$ (SMU.1985), a homologue of the $B$. subtilis com $G B$ gene that encodes part of an $\mathrm{ABC}$ transporter essential for DNA bindinguptake during competence in $S$. mutans [46]. Interestingly, a $\operatorname{com} Y B$ mutant of $S$. mutans was shown to be unaffected in competence signaling, but showed reduced biofilm formation, which was thought to be a function of its inability to bind biofilm matrix eDNA [47]. Since the lytS mutant displayed an increase in $\operatorname{com} Y B$ expression (Additional file 1: Table S1 and Additional file 2: Table S2), we hypothesized that this strain may display alterations in its ability to form biofilm and/or its transformability during genetic competence. However, the lytS mutant did not display any appreciable difference in its ability to form static biofilm in the presence of glucose or sucrose (data not shown), and likewise, did not display a difference in its ability to uptake plasmid DNA in a quantitative competence assay, relative to the wild-type strain (Figure 3). Since $\operatorname{lrg} A B$ expression is so strongly regulated by LytST, the ability of isogenic $\operatorname{lrg} A, \operatorname{lrg} B$, and $\operatorname{lrg} A B$ mutants to uptake plasmid DNA via competence was also assessed (Figure 3 ). Of all the mutants tested, the $\operatorname{lrg} A$ mutant was the most severely impaired in its ability to uptake plasmid DNA relative to the parental strain, displaying a 26- and 24-fold decrease in transformation efficiency in the presence and absence of competence-stimulating peptide (CSP), respectively (Figure 3), suggesting that LrgA is somehow involved in genetic transformation in a CSP-independent manner. This finding has particular significance considering that $\operatorname{Lrg} \mathrm{AB}$ has been linked to regulation of cell death and lysis in S. aureus [21,29] and S. mutans [37], and these physiological processes are also extremely important during natural competence. It is interesting to note that, similar to the competence results described here, the $\operatorname{lrg} A$ mutant was previously shown to display decreased glucose-dependent biofilm formation and decreased glucosyltransferase production, whereas the $\operatorname{lrg} B$ and $\operatorname{lrg} A B$ mutants behaved in a manner similar to the parental strain [37]. These phenotypic patterns suggest that the presence of $\operatorname{LrgB}$ alone, rather than the lack of LrgA, may be responsible for the biofilm and competence phenotypes observed in the $\operatorname{lrg} A$ mutant.

\section{Effect of LytST on oxidative stress tolerance}

Previously, our investigations disclosed a strong link between oxidative stress tolerance and the Cid/Lrg system

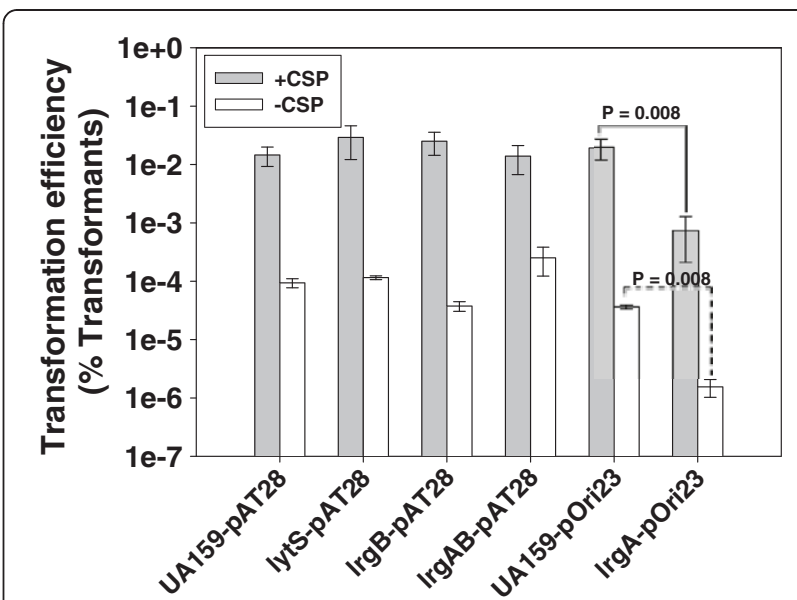

Figure 3 Transformation efficiencies of UA159 and isogenic lytS and Irg mutants. To compare the ability of UA159 and its isogenic lytS, $\operatorname{lrg} A$, $\operatorname{lrg} B$, and $\operatorname{lrg} A B$ mutants to take up exogenously-added plasmid DNA, a quantitative competence assay was performed on $n=4-6$ biological replicates of each strain as described in Methods [83]. Plasmid pAT28 [encoding spectinomycin resistance; [84] was used to assess transformation efficiency in UA159, lytS, $\operatorname{lrg} B$, and $\operatorname{lrg} A B$

mutants. Because the $\operatorname{Irg} A$ mutant was generated with a spectinomycin-resistance cassette [37], plasmid pORi23 [encoding erythromycin resistance; [85]] was used to assess transformation efficiency in UA159 and IrgA mutant. Transformation efficiencies ( $Y$ axis) in the presence (grey bars) and absence (white bars) of CSP are expressed as the percentage of transformants (CFU/ml on BHI + selective antibiotic) among total viable cells (CFU/ml on BHI). Error bars represent SEM. Brackets with $P$ values denote statisticallysignificant differences between two samples (Mann-Whitney Rank Sum Test).

[37], a role for these genes that had not been described in other organisms. Specifically, we found that $\operatorname{lrg} A B$, $\operatorname{lrg} B, \operatorname{cid} A B$, and $\operatorname{cid} B$ mutants exhibited reduced growth in the presence of paraquat, and growth of $\operatorname{lrg} A B, \operatorname{cid} A B$, and $c i d B$ mutants on BHI agar plates in aerobic conditions was almost completely inhibited [37]. It is therefore interesting to note that in the lytS microarray results (Additional file 2: Table S2), genes encoding antioxidant and DNA repair/recombination enzymes were significantly upregulated in the lytS mutant in late exponential phase. These included $y g h U$ and $t p x$, encoding the putative anti-oxidant enzymes glutathione $\mathrm{S}$-transferase and thiol peroxidase, respectively, as well as recJ, which encodes a single-stranded DNA exonuclease protein that facilitates DNA repair in response to oxidative stress [48-51]. To further investigate the effect of $\operatorname{ly} t S$ and $\operatorname{lrg} A B$ on oxidative stress tolerance, wild-type, lytS, and $\operatorname{lrg} A B$ mutants were grown as planktonic static $\mathrm{BHI}$ cultures in aerobic atmosphere and in the presence and absence of $\mathrm{H}_{2} \mathrm{O}_{2}$ (Figure 4). When challenged with $\mathrm{H}_{2} \mathrm{O}_{2}$, UA159 experienced an increased lag phase of growth, and the overall OD of the culture was 10-25\% less than the untreated culture until $20 \mathrm{~h}$ growth. Under these assay conditions, the $\operatorname{lrg} A B$ mutant displayed a 


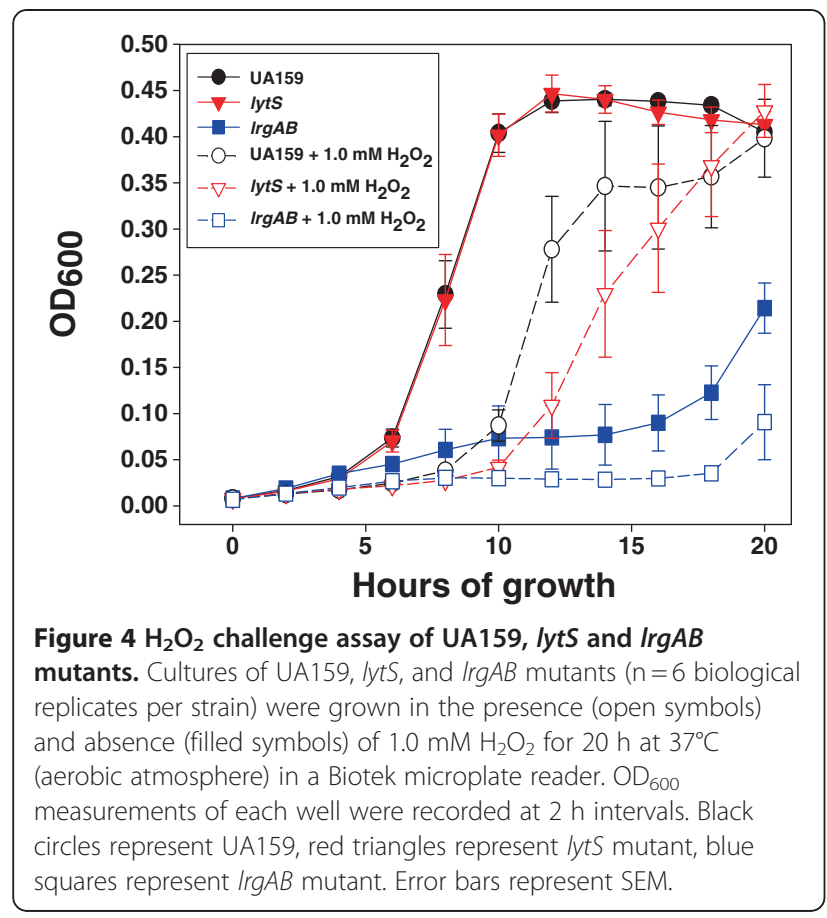

dramatic growth defect in both the presence and absence of $\mathrm{H}_{2} \mathrm{O}_{2}$. It is interesting to note that this aerobic growth defect was also previously observed when the $\operatorname{lrg} A B$ mutant was grown in aerobic atmosphere on BHI agar plates [37]. The lytS mutant displayed an increased lag in growth relative to UA159 when cultured in the presence of $\mathrm{H}_{2} \mathrm{O}_{2}$, but $\mathrm{OD}$ values were comparable to the wild-type strain by $16 \mathrm{~h}$ growth. These results suggest that the LytST regulon impacts the ability of cells to grow under conditions of oxidative stress.

The cell-permeable fluorescent dye $\mathrm{CM}-\mathrm{H}_{2} \mathrm{DCFDA}$ (Invitrogen Molecular Probes) was also used to assess intracellular ROS in UA159 and the lytS mutant (Figure 5). This fluorescent compound is oxidized in the presence of $\mathrm{H}_{2} \mathrm{O}_{2}$ and other reactive oxygen species (ROS) and is considered a general indicator of intracellular oxidative stress [52,53]. This analysis revealed that stationary-phase cultures of the wild-type and lytS mutant strains had similar "endogenous" intracellular levels of ROS (Figure 5, light grey bars). When stationaryphase cells from each strain were loaded with $\mathrm{CM}$ $\mathrm{H}_{2}$ DCFDA and then challenged with $5 \mathrm{mM} \mathrm{H}_{2} \mathrm{O}_{2}$ (Figure 5, dark grey bars), a greater increase in fluorescence was observed in the lytS mutant relative to UA159 $(P=0.009$, Mann-Whitney Rank Sum Test), suggesting that loss of LytS has an impact on the ability of the cells to detoxify $\mathrm{H}_{2} \mathrm{O}_{2}$ and/or other intracellular ROS.

\section{Discussion}

The transcriptome analyses presented in this study have revealed that the LytST two-component system has a

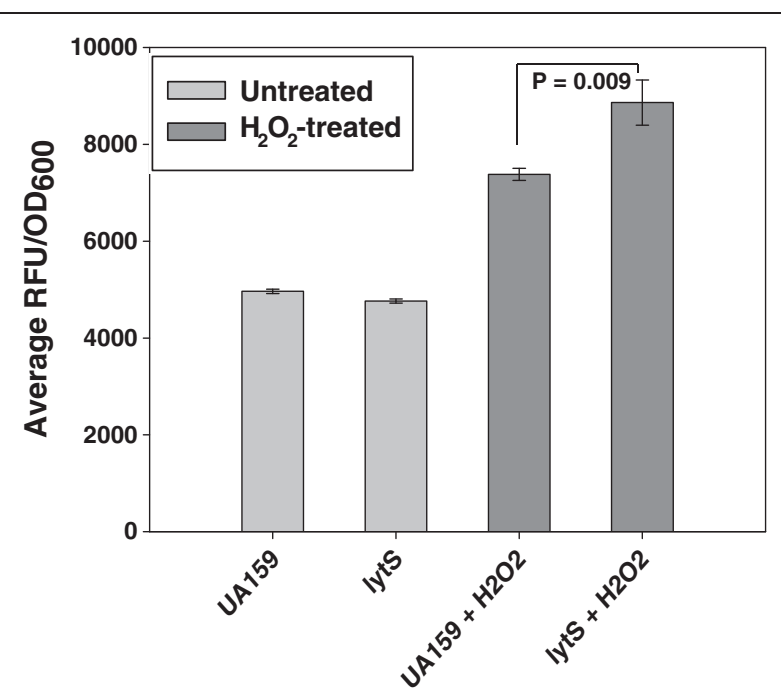

Figure 5 Measurement of intracellular ROS in UA159 and lytS mutant by $\mathrm{CM}-\mathrm{H}_{2}$ DCFDA staining. Cells were harvested from $20 \mathrm{~h}$ $\mathrm{BHI}$ cultures of $\mathrm{UA} 159$ and isogenic lyts mutant grown at $37^{\circ} \mathrm{C} 5 \%$ $\mathrm{CO}_{2}$ ( $\mathrm{n}=3-6$ biological replicates each), resuspended in HBSS containing $5 \mu \mathrm{M} \mathrm{CM}-\mathrm{H}_{2} \mathrm{DCFDA}$, and incubated at $37^{\circ} \mathrm{C}$ to load the cells with stain. After 60 min incubation, cell suspensions were centrifuged, washed once in HBSS buffer, and then resuspended in HBSS buffer alone (light grey bars) or in HBSS containing $5 \mathrm{mM}$ $\mathrm{H}_{2} \mathrm{O}_{2}$ (dark grey bars). Each suspension was transferred to wells of an optically-clear 96 well plate, and incubated at $37^{\circ} \mathrm{C}$ in a microplate reader. Cell fluorescence (as measured by relative fluorescence units; RFU) and the $\mathrm{OD}_{600}$ of each well was recorded after $30 \mathrm{~min}$ incubation. RFU measurements are expressed per $\mathrm{OD}_{600}$ of each well to account for any subtle variations in cell density. Error bars represent SEM. Brackets with $P$ values denote statistically-significant differences between two samples (Mann-Whitney Rank Sum Test).

widespread effect on gene expression in S. mutans. A much higher number of transcripts were affected by the lyt $S$ mutation in late exponential phase and the magnitude of changes in expression was greater $(n=136$ genes, Additional file 2: Table S2) relative to early-exponential phase $(n=40$ genes, Additional file 1: Table S1), where most genes exhibited only a modest (1-2 fold) change in expression. These differences in gene expression patterns are unlikely to be an indirect function of altered $\operatorname{lrg} A B$ expression in the $\operatorname{lyt} S$ mutant, as expression of lytS-regulated genes was unaltered in an $\operatorname{lrg} A B$ mutant relative to the wild-type strain (Table 1). Taken together, these observations suggest that LytST exerts control over its transcriptome in a growth-phase dependent manner, and to our knowledge, this is the first study that has compared the scope of LytST regulation at different phases of growth. Interestingly, RNA microarray studies of lyt mutants have also been performed in $S$. aureus [38], S. epidermidis [40], and B. subtilis [42]. As we have observed here in S. mutans, a global effect of LytST on gene expression was also noted in S. aureus and S. epidermidis $[38,40]$. In $S$. aureus, LytST appeared to exert 
primarily positive effects on gene expression in exponential phase when aerobic cultures were grown in media containing excess $(35 \mathrm{mM})$ glucose, as only 7 genes were found to be upregulated in the lytS mutant [38]. In $S$. epidermidis, a large number of genes were up- or down-regulated as a function of the presence of LytST during exponential phase during aerobic growth in medium containing $12 \mathrm{mM}$ glucose [40]. In contrast, mutation of lytS only appeared to affect the expression of lytST itself and genes encoding $\operatorname{lrg} A B$ and $\operatorname{cid} A B$ homologues in B. subtilis [42]. However, due to the differences in growth conditions used (glucose levels and/or culture aeration) and the differing metabolic pathways present in these organisms, it is difficult to establish direct correlations between these studies and the $S$. mutans microarray results presented here.

As demonstrated previously [37], expression of $\operatorname{lrg} A B$ was also shown to be tightly controlled by the LytST two-component system in S. mutans in this study. Specifically, we have found that LytST-dependent expression of $\operatorname{lrg} A B$ is regulated in part by glucose metabolism and oxygen in $S$. mutans (Figure 1). Furthermore, control of $\operatorname{lrg} A B$ expression by LytST appears to be highly growthphase dependent: $\operatorname{lrg} A B$ expression in the $\operatorname{lytS}$ mutant exhibited only a modest decrease in expression in early exponential phase (0.49 relative to UA159, Additional file 1: Table $\mathrm{S} 1$ ), whereas $\operatorname{lrg} A B$ expression was downregulated some 200 -fold in the $l y t S$ mutant at late exponential phase (Additional file 2: Table S2). Alternatively, it is possible that control of $\operatorname{lrg} A B$ expression by LytST is related to higher glucose availability during early exponential phase. Although detailed mechanistic studies have not yet been performed, there is mounting evidence that these proteins are critical for oxidative stress resistance in $S$. mutans: (1) $\operatorname{lrg} A B$ expression is highly regulated by oxygen ([11] and this study); (2) a $\operatorname{lrg} A B$ mutant was defective in aerobic growth on BHI agar plates [37]; (3) a $\operatorname{lrg} A B$ mutant displayed a decreased growth rate in the presence of paraquat (a superoxide-generating agent) relative to the wild-type strain [37]; and (4) a $\operatorname{lrg} A B \mathrm{mu}-$ tant displayed a strong growth defect during static planktonic aerobic growth in BHI in the presence and absence of $\mathrm{H}_{2} \mathrm{O}_{2}$ challenge (this study). Interestingly, a link between $\operatorname{LrgAB}$ and oxidative stress was also demonstrated in $S$. aureus, where $\operatorname{lytSR}$ and $\operatorname{lrgAB}$ expression were upregulated 2-5 fold in response to azurophilic granule proteins, $\mathrm{H}_{2} \mathrm{O}_{2}$, and hypochlorite [54].

In agreement with a role for $\operatorname{LrgAB}$ in oxidative stress resistance, several LytST-regulated genes identified in this study have also been implicated in bacterial oxidative stress responses. Upregulated potential oxidative stress genes include $y g h U$, a putative anti-oxidant enzyme [50], tpx, a predicted thiol peroxidase [55], and recJ, a single-stranded DNA exonuclease protein that facilitates DNA repair in response to oxidative stress
[51]. Conversely, several genes belonging to the TnSMu2 gene cluster (SMU.1334c - SMU.1359) were downregulated in the lytS mutant. These genes are annotated as encoding a series of gene products involved in bacitracin and gramicidin synthesis [56], but more recently have been shown to be responsible for nonribosomal peptide and polyketide (NRP/PK) biosynthesis of a pigment that enhances aerobic growth and tolerance to $\mathrm{H}_{2} \mathrm{O}_{2}$ challenge in S. mutans UA159 [45]. The altered expression of one or more of these genes may explain, in part, the increased ROS accumulation that was observed in the lytS mutant when challenged with $\mathrm{H}_{2} \mathrm{O}_{2}$ (Figure 5). Furthermore, it was previously found that a two-component system responsible for positive regulation of the NRP/ PK genes was located on the TnSMu2 genomic island of UA140 but not in UA159 [45]. This observation, combined with the microarray results performed here (Additional file 1: Table S1 and Additional file 2: Table S2) suggest that LytST may have taken over some of the regulatory functions of this non-core-genome two-component system that is missing in UA159.

Interestingly, $\mathrm{H}_{2} \mathrm{O}_{2}$ has also been shown to be a potent stimulator of competence and eDNA release in $S$. sanguinis [57], S. gordonii [57,58], and S. pneumoniae [59]. Although the effects of $\mathrm{H}_{2} \mathrm{O}_{2}$ on $S$. mutans competence, cell lysis, and eDNA release have not been directly measured, it has been shown that growth under aerobic conditions promotes competence in S. mutans [47], and that expression of competence-related genes is upregulated during aerobic growth [11]. The results presented here have demonstrated that expression of $\operatorname{com} Y B$, a gene encoding a component of the DNA-binding uptake system in S. mutans [47] was upregulated 2-fold in early exponential phase and 22-fold in late exponential phase in the lytS mutant (Additional file 1: Table S1 and Additional file 2: Table S2). The significance of highlevel com $Y B$ expression in the lytS mutant at late exponential phase is unclear, given that maximal $S$. mutans competence develops in actively-growing populations [60,61]. Accordingly, upregulation of $\operatorname{com} Y B$ expression did not correlate with increased transformability of the lytS mutant under the conditions tested in this study (Figure 3). However, it was found that the $\operatorname{lrg} A$ mutant displayed a significant reduction in competence. It has been recently reported that only a subpopulation of $S$. mutans culture lyses in response to CSP, and this lysis event is controlled in part by the CipB bacteriocin and the CipI immunity protein [62]. Subsequent microarray analysis of a cipI (immunity protein) mutant showed that both $\operatorname{lytST}$ and $\operatorname{lrgAB}$ expression were highly upregulated in the cipI mutant [63]. These results, combined with the fact that $\operatorname{LrgA} / \mathrm{B}$ has been shown to be involved in regulating cell lysis and eDNA release in $S$. aureus $[21,29]$, lends strong support to the idea that LrgA plays 
an important role during competence, possibly by altering membrane permeability or by modulating murein hydrolase activity.

The S. mutans com $Y$ operon consists of nine cotranscribed genes, of which the first eight genes are either essential to or significantly affect competence [46]. The ninth gene of this operon is predicted to encode acetate kinase (AckA), an enzyme that catalyzes the inter-conversion of acetyl-phosphate and acetate [46,64]. For micro-organisms with an inefficient or incomplete TCA cycle such as $S$. mutans, AckA-mediated conversion of acetyl-phosphate to acetate is thought to be a critical mechanism of generating ATP [reviewed in [65]]. Since ackA ( $\operatorname{com} Y I)$ was previously found to be upregulated in S. mutans during aerated growth [11], it is possible that LytST is involved in the regulation of energy generation through the phosphate acetyltransferase (Pta)-AckA pathway during aerobic growth and/or during oxidative stress. In this respect, it has recently been reported that an S. mutans pta mutant was more susceptible to both acid and oxidative stresses [66].

The ability of $S$. mutans to combat $\mathrm{H}_{2} \mathrm{O}_{2}$ stress is critical for its survival in the oral cavity, yet $\mathrm{H}_{2} \mathrm{O}_{2}$ detoxifying mechanisms and their regulation have not been extensively-characterized in this organism, limited primarily to the ScnRK and VicRK two-component systems [67,68], $\operatorname{rop} A$ [69], $\operatorname{brp} A$ [70], $\operatorname{lux} S$ [71] and genomic island $\mathrm{TnSMu} 2$ [45]. $\mathrm{H}_{2} \mathrm{O}_{2}$ has been shown to have potent antibacterial effects on S. mutans [72], and it is thought that $\mathrm{H}_{2} \mathrm{O}_{2}$ produced by other oral streptococcal species serves as an antagonist against $S$. mutans. For example, $S$. sanguinis and S. gordonii have been shown to produce $\mathrm{H}_{2} \mathrm{O}_{2}$ via pyruvate oxidase under aerobic growth conditions, and this $\mathrm{H}_{2} \mathrm{O}_{2}$ production allows them to compete effectively against $S$. mutans when co-cultured under aerobic growth conditions [57]. It is therefore possible that the $S$. mutans LytST regulon mediates a pleiotropic protective response against these $\mathrm{H}_{2} \mathrm{O}_{2}$-producing niche competitors. On-going and future studies by our group will focus on experimental testing of this hypothesis.

\section{Conclusions}

In summary, the LytST two-component system has been shown to have a pleiotropic effect on gene expression in S. mutans. This is congruent with microarray analyses of lytS mutants in S. aureus [38] and S. epidermidis [40]. However, unlike in other organisms, we have been able to identify a pattern of LytS-mediated gene expression that suggests a role for this regulon in responding to oxidative/ $\mathrm{H}_{2} \mathrm{O}_{2}$ stress. Although we have not yet been able to identify the external signal to which LytS responds, it is likely linked to an oxidative stress-sensing mechanism, such as $\mathrm{H}_{2} \mathrm{O}_{2}$ mediated membrane damage (ie. lipid peroxidation) via its large number of transmembrane domains, or oxygen/ROS interactions with its predicted cytoplasmic GAF domain, a ubiquitous signaling domain that has been shown to detect changes in the redox state of bound iron or oxygen in Mycobacterium tuberculosis [73-75]. Establishing mechanistic links between the LytST regulon, $\mathrm{H}_{2} \mathrm{O}_{2}$ resistance, and competence regulation will provide valuable new insights into $S$. mutans survival and virulence in the oral cavity.

\section{Methods}

Bacterial strains, media, and growth conditions

For all experiments, frozen glycerol stocks of S. mutans UA159 and its isogenic lytS (SAB111; $\Delta l y t S:: \mathrm{NPKm}^{\mathrm{r}}$ ), $\operatorname{lrg} A \quad\left(\mathrm{SAB} 113 ; \quad \Delta \operatorname{lrg} A:: \mathrm{NPSp}^{\mathrm{r}}\right), \operatorname{lrgB}$ (SAB119; $\triangle \operatorname{lrgB::}$ $\left.\mathrm{NPEm}{ }^{\mathrm{r}}\right)$, and $\operatorname{lrg} A B\left(\mathrm{SAB} 115 ; \triangle \operatorname{lrg} A B:: \Omega \mathrm{Km}^{\mathrm{r}}\right)$ mutants [created previously in [37] were freshly streaked for isolation on either Todd Hewitt Yeast Extract (THYE) or Brain Heart Infusion (BHI), containing selective antibiotic as appropriate: kanamycin $(\mathrm{Km})-1000 \mu \mathrm{g} / \mathrm{ml}$, erythromycin $(\mathrm{Em})$ - $10 \mu \mathrm{g} / \mathrm{ml}$, spectinomycin $(\mathrm{Sp})$ $1000 \mu \mathrm{g} / \mathrm{ml})$. With the exception of SAB115 $(\operatorname{lrg} A B \mathrm{mu}-$ tant), all mutants were created using non-polar (NP) antibiotic-resistance markers [37]. Unless otherwise indicated, all $S$. mutans cultures were grown as static cultures in $\mathrm{BHI}$ or $\mathrm{THYE}$ broth at $37^{\circ} \mathrm{C}$ and $5 \% \mathrm{CO}_{2}$.

\section{Analysis of $\operatorname{Irg} A B$ expression}

To measure the effects of oxygen and glucose on $\mathrm{lrg}$ expression, overnight THYE cultures of UA159 and the lytS mutant $(\mathrm{n}=3$ biological replicates each, grown at 0 $\mathrm{RPM}, 37^{\circ} \mathrm{C}$ and $5 \% \mathrm{CO}_{2}$ ) were each inoculated to an $\mathrm{OD}_{600}=0.02$ into THYE containing either $11 \mathrm{mM}$ or $45 \mathrm{mM}$ glucose. For "low $\mathrm{O}_{2}$ " cultures, $2 \mathrm{~L}$ culture flasks each containing $400 \mathrm{ml}$ media were grown at $0 \mathrm{RPM}$, $37^{\circ} \mathrm{C}$, and $5 \% \mathrm{CO}_{2}$. For aerobic cultures, $500 \mathrm{ml}$ culture flasks each containing $100 \mathrm{ml}$ media were grown at $37^{\circ} \mathrm{C}$ and 250 RPM. Total RNA was isolated from all cultures sampled at exponential $\left(\mathrm{EP} ; \mathrm{OD}_{600}=0.2-0.4\right)$ and stationary (SP; OD600 =1.4 - 1.7) growth phase, with an RNeasy Mini kit (Qiagen) and FASTPREP (MP Biomedicals) using previously-described methods [76]. Real-time reverse-transcriptase $\mathrm{PCR}$ and data analysis using $\operatorname{lrg} A$ and $16 \mathrm{~S}$ primers was performed using previously described primers [37] and methods [77]. Fold-change expression of $\operatorname{lrg} A$ and $16 \mathrm{~S}$ under each growth condition (11 $\mathrm{mM}$ low $-\mathrm{O}_{2}, 11 \mathrm{mM}$ aerobic, $45 \mathrm{mM}$ low $-\mathrm{O}_{2}$, $45 \mathrm{mM}$ aerobic) was calculated by dividing the gene copy number of each test sample by the average gene copy number of UA159 EP. Data was then normalized by dividing each $\operatorname{lrg} A$ fold-change expression value by its corresponding $16 \mathrm{~S}$ fold-change expression value.

\section{RNA microarray analysis of UA159 and lytS mutant}

To assess the effect of LytS on global gene expression, overnight BHI cultures of UA159 and lytS mutant $(\mathrm{n}=3$ 
biological replicates per strain) were diluted to an $\mathrm{OD}_{600}=0.02$ in $\mathrm{BHI}$, and grown as static cultures at $37^{\circ} \mathrm{C}$ and $5 \% \mathrm{CO}_{2}$. Total RNA was isolated from each culture at early-exponential $\left(\mathrm{OD}_{600}=0.15\right)$ and late exponential phase $\left(\mathrm{OD}_{600}=0.9\right)$, using previously-published methods [77]. RNA microarray analysis was performed using S. mutans UA159 microarrays provided by The Institute for Genomic Research, and previously-described methods and data analysis $[11,70,78]$. In brief, $2 \mu \mathrm{g}$ total bacterial RNA was used in each reverse-transcription and cDNA labeling reaction (performed as described in $[70,78])$, and a single preparation from each culture was hybridized per microarray slide in a Maui hybridization chamber (BioMicro Systems, Salt Lake City, UT). The resulting microarray slides were scanned, analyzed, and normalized using TIGR Spotfinder software (http://www. tigr.org/software/), and in-slide replicate analysis was performed with the TIGR microarray data analysis system (MIDAS; http://www.tigr.org/software/). Statistical analysis was carried out with BRB array tools (http:// linus.nci.nih.gov/BRB-ArrayTools.html/) with a cutoff $P$ value $<0.005$ for the early exponential-phase data and $P$ $<0.001$ for the late exponential phase data. To validate the microarray results, real-time quantitative RT-PCR was performed on a subset of the differentially-expressed genes, as described previously [77,79]. All real-time PCR primers were designed with Beacon Designer 4.0 software (Premier Biosoft International, Palo Alto, CA), and standard curves for each gene were prepared as published elsewhere [80]. The microarray data obtained from these studies have been deposited to NCBI's gene expression omnibus (GEO) [81] (GEO Accession \#GSE39470) and comply with MIAME guidelines [82].

\section{Quantitative competence assays}

To compare the ability of UA159 and its isogenic lytS, $\operatorname{lrg} A, \operatorname{lrg} B$, and $\operatorname{lrg} A B$ mutants to take up exogenouslyadded plasmid DNA, a quantitative competence assay was performed on $n=4-6$ biological replicates of each strain using a previously-published protocol [83] with the following modifications: Overnight cultures of each strain were diluted to an $\mathrm{OD}_{600}=0.02$ in $\mathrm{BHI}$, and grown in a 96-well plate to an $\mathrm{OD}_{600}=0.15$ prior to addition of $500 \mathrm{ng}$ plasmid DNA with and without $100 \mathrm{ng}$ CSP. Plasmid pAT28 (encoding spectinomycin resistance; [84]) was used to assess transformation efficiency in UA159, $\operatorname{lyt} S, \operatorname{lrg} B$, and $\operatorname{lrg} A B$ mutants. Because the $\operatorname{lrg} A$ mutant was generated with a spectinomycin-resistance cassette [37], plasmid pORi23 [encoding erythromycin resistance; [85]] was used to assess transformation efficiency in UA159 and $\operatorname{lrgA}$ mutant. After $2.5 \mathrm{~h}$ incubation in the presence of plasmid DNA +/- CSP, cultures were serially diluted and plated on BHI agar with and without selective antibiotic. CFU/ml of each culture were enumerated after $48 \mathrm{~h}$ growth at $37^{\circ} \mathrm{C}$ and $5 \% \mathrm{CO}_{2}$, and transformation efficiencies were calculated as the percentage of transformants ( $\mathrm{CFU} / \mathrm{ml}$ on $\mathrm{BHI}+$ selective antibiotic) among total viable cells (CFU/ml on BHI).

\section{$\mathrm{H}_{2} \mathrm{O}_{2}$ assays}

To assess of the ability of UA159, lytS, and $\operatorname{lrg} A B$ mutants to grow in the presence of $\mathrm{H}_{2} \mathrm{O}_{2}$, overnight cultures of each strain ( $n=6$ biological replicates) were each diluted 40-fold into BHI. $1 \mathrm{ml}$ aliquots of each diluted culture were either untreated or challenged with $1 \mathrm{mM}$ $\mathrm{H}_{2} \mathrm{O}_{2}$. Aliquots of each $(500 \mu \mathrm{l}$ per well, 2 wells total) were then immediately transferred to an optically-clear 48-well tissue culture plate (Costar 3548), which was incubated for $20 \mathrm{~h}$ at $37^{\circ} \mathrm{C}$ (aerobic atmosphere) in a Biotek Synergy microplate reader. $\mathrm{OD}_{600}$ measurements of each well were recorded at $2 \mathrm{~h}$ intervals.

\section{Oxidative stress measurements}

To assess intracellular oxidative stress in UA159 and lytS mutant, single isolated colonies of each strain $(n=3-6$ biological replicates per strain) were inoculated into culture tubes containing $4 \mathrm{ml} \mathrm{BHI}$, and grown in "low- $\mathrm{O}_{2}$ " conditions $\left(37^{\circ} \mathrm{C}, 0 \mathrm{RPM}, 5 \% \mathrm{CO}_{2}\right)$. After $20 \mathrm{~h}$ growth, $2 \times 1 \mathrm{ml}$ aliquots of each culture were harvested by centrifugation in a microcentrifuge ( $3 \mathrm{~min}$ at 13,000 RPM). The culture supernatants were discarded, and cell pellets were each resuspended in $1 \mathrm{ml}$ Hanks Buffer (HBSS) containing $5 \mu \mathrm{M}$ chloromethyl 2/,7/-dichlorofluorescein diaceate (CM- $\mathrm{H}_{2} \mathrm{DCFDA}$; Invitrogen Molecular Probes), a cell-permeable fluorescent compound that is oxidized in the presence of $\mathrm{H}_{2} \mathrm{O}_{2}$ and other reactive oxygen species (ROS) and is considered a general indicator of cellular oxidative stress [52,53]. Cell suspensions were incubated at $37^{\circ} \mathrm{C}$ for $60 \mathrm{~min}$ to "load" the cells with $\mathrm{CM}-\mathrm{H}_{2} \mathrm{DCFDA}$, followed by centrifugation (3 $\mathrm{min}$ at 13,000 RPM). Supernatants were discarded, and cell pellets were washed once with HBSS prior to resuspension in $1 \mathrm{ml} \mathrm{HBSS}$ or in $1 \mathrm{ml}$ HBSS containing $5 \mathrm{mM} \mathrm{H} \mathrm{H}_{2} \mathrm{O}_{2}$. Each cell suspension was transferred into triplicate wells $(200 \mu \mathrm{l}$ per well $)$ of an optically-clear 96 well plate (Costar 3614), and the plate was transferred to a Biotek Synergy microplate reader. Fluorescence in relative fluorescence units (RFU; using 492-495 nm excitation and 517-527 $\mathrm{nm}$ emission) and $\mathrm{OD}_{600}$ readings of each well were recorded after $30 \mathrm{~min}$ incubation at $37^{\circ} \mathrm{C}$.

\section{Statistical analysis}

All statistical analyses, unless otherwise indicated, were performed using Sigmaplot for Windows 11.0 software (Build 11.0.0.75, Systat Software, Inc.). 


\section{Additional files}

Additional file 1: Table S1. Genes differentially expressed by loss of LytS at early-exponential phase $(P<0.005)$.

Additional file 2: Table S2. Genes differentially expressed by loss of LytS at late exponential phase $(P<0.001)$.

\section{Competing interests}

The authors declare that they have no competing interests.

\section{Authors' contributions}

SJA carried out the RNA microarray experiments and associated data analysis, performed all real-time PCR studies, participated in the conception and design of the study, and helped draft the manuscript. MDQ carried out all of the RNA isolations for comparing the effects of glucose and oxygenation on $\operatorname{Irg} A B$ expression. ER optimized and carried out all of the quantitative competence assays. RAB participated in the design and coordination of the study, and helped draft the manuscript. KCR participated in the conception and design of the study, performed the $\mathrm{H}_{2} \mathrm{O}_{2}$ assays, intracellular ROS measurements, and drafted the manuscript. All authors read and approved the final manuscript.

\section{Acknowledgements}

This work was supported by a University of Florida HHMI-Science for Life Undergraduate Research Award to M. D. Q., NIH-NIDCR grants R03 DE019179 (KCR) and R01 DE13239 (RAB). We thank Christopher Browngardt for technical assistance in editing microarray data.

\section{Author details}

${ }^{1}$ Department of Oral Biology, College of Dentistry, University of Florida, Gainesville, FL 32611, USA. ²Department of Microbiology and Cell Science, College of Agricultural and Life Sciences, University of Florida, Gainesville, FL 32611, USA.

Received: 29 May 2012 Accepted: 21 August 2012

Published: 1 September 2012

\section{References}

1. Deonarine B, Lazar J, Gill MV, Cunha BA: Quadri-valvular endocarditis caused by Streptococcus mutans. Clin Microbiol Infect 1997, 3(1):139-141.

2. Biswas S, Bowler IC, Bunch C, Prendergast B, Webster DP: Streptococcus mutans infective endocarditis complicated by vertebral discitis following dental treatment without antibiotic prophylaxis. J Med Microbiol 2010, 59(Pt 10):1257-1259.

3. Ullman RF, Miller SJ, Strampfer MJ, Cunha BA: Streptococcus mutans endocarditis: report of three cases and review of the literature. Heart Lung 1988, 17(2):209-212.

4. Vose JM, Smith PW, Henry M, Colan D: Recurrent Streptococcus mutans endocarditis. Am J Med 1987, 82(3 Spec No):630-632.

5. Yamashita Y, Bowen WH, Burne RA, Kuramitsu HK: Role of the Streptococcus mutans gtf genes in caries induction in the specificpathogen-free rat model. Infect Immun 1993, 61(9):3811-3817.

6. Yamashita Y, Takehara T, Kuramitsu HK: Molecular characterization of a Streptococcus mutans mutant altered in environmental stress responses. J Bacteriol 1993, 175(19):6220-6228.

7. Ooshima T, Matsumura M, Hoshino T, Kawabata S, Sobue S, Fujiwara T: Contributions of three glycosyltransferases to sucrose-dependent adherence of Streptococcus mutans. J Dent Res 2001, 80(7):1672-1677.

8. Munro CL, Michalek SM, Macrina FL: Sucrose-derived exopolymers have site-dependent roles in Streptococcus mutans-promoted dental decay. FEMS Microbiol Lett 1995, 128(3):327-332.

9. Ahn SJ, Browngardt CM, Burne RA: Changes in biochemical and phenotypic properties of Streptococcus mutans during growth with aeration. Appl Environ Microbiol 2009, 75(8):2517-2527.

10. Ahn SJ, Burne RA: Effects of oxygen on biofilm formation and the AtlA autolysin of Streptococcus mutans. J Bacteriol 2007, 189(17):6293-6302.

11. Ahn SJ, Wen ZT, Burne RA: Effects of oxygen on virulence traits of Streptococcus mutans. J Bacteriol 2007, 189(23):8519-8527.
12. Abranches J, Nascimento MM, Zeng L, Browngardt CM, Wen ZT, Rivera MF, Burne RA: CcpA regulates central metabolism and virulence gene expression in Streptococcus mutans. J Bacterio/ 2008, 190(7):2340-2349.

13. Browngardt CM, Wen ZT, Burne RA: RegM is required for optimal fructosyltransferase and glucosyltransferase gene expression in Streptococcus mutans. FEMS Microbiol Lett 2004, 240(1):75-79.

14. Wen ZT, Burne RA: Functional genomics approach to identifying genes required for biofilm development by Streptococcus mutans. Appl Environ Microbiol 2002, 68(3):1196-1203.

15. Bitoun JP, Nguyen AH, Fan Y, Burne RA, Wen ZT: Transcriptional repressor Rex is involved in regulation of oxidative stress response and biofilm formation by Streptococcus mutans. FEMS Microbiol Lett 2011, 320(2):110-117.

16. Wang B, Kuramitsu HK: A pleiotropic regulator, Frp, affects exopolysaccharide synthesis, biofilm formation, and competence development in Streptococcus mutans. Infect Immun 2006, 74(8):4581-4589.

17. Rice KC, Mann EE, Endres JL, Weiss EC, Cassat JE, Smeltzer MS, Bayles KW The cidA murein hydrolase regulator contributes to DNA release and biofilm development in Staphylococcus aureus. Proc Natl Acad Sci U S A 2007, 104(19):8113-8118.

18. Thomas VC, Hiromasa Y, Harms N, Thurlow L, Tomich J, Hancock LE: A fratricidal mechanism is responsible for eDNA release and contributes to biofilm development of Enterococcus faecalis. $\mathrm{Mol}$ Microbiol 2009, 72(4):1022-1036.

19. Harmsen M, Lappann M, Knochel S, Molin S: Role of extracellular DNA during biofilm formation by Listeria monocytogenes. Appl Environ Microbiol 2010, 76(7):2271-2279.

20. Whitchurch CB, Tolker-Nielsen T, Ragas PC, Mattick JS: Extracellular DNA required for bacterial biofilm formation. Science 2002, 295(5559):1487.

21. Mann EE, Rice KC, Boles BR, Endres JL, Ranjit D, Chandramohan L, Tsang LH, Smeltzer MS, Horswill AR, Bayles KW: Modulation of eDNA release and degradation affects Staphylococcus aureus biofilm maturation. PLoS One 2009, 4(6):e5822.

22. Lappann M, Claus H, van Alen T, Harmsen M, Elias J, Molin S, Vogel U: A dual role of extracellular DNA during biofilm formation of Neisseria meningitidis. Mol Microbiol 2010, 75(6):1355-1371.

23. Mai-Prochnow A, Evans F, Dalisay-Saludes D, Stelzer S, Egan S, James S, Webb JS, Kjelleberg S: Biofilm development and cell death in the marine bacterium Pseudoalteromonas tunicata. Appl Environ Microbiol 2004, 70(6):3232-3238.

24. Webb JS, Thompson LS, James S, Charlton T, Tolker-Nielsen T, Koch B, Givskov M, Kjelleberg S: Cell death in Pseudomonas aeruginosa biofilm development. J Bacteriol 2003, 185(15):4585-4592.

25. Barraud N, Hassett DJ, Hwang SH, Rice SA, Kjelleberg S, Webb JS: Involvement of nitric oxide in biofilm dispersal of Pseudomonas aeruginosa. J Bacterio/ 2006, 188(21):7344-7353.

26. Rice KC, Bayles KW: Molecular control of bacterial death and lysis. Microbiol Mol Biol Rev 2008, 72(1):85-109. table of contents.

27. Rice KC, Firek BA, Nelson JB, Yang SJ, Patton TG, Bayles KW: The Staphylococcus aureus cidAB operon: evaluation of its role in regulation of murein hydrolase activity and penicillin tolerance. J Bacterio/ 2003, 185(8):2635-2643.

28. Rice KC, Nelson JB, Patton TG, Yang SJ, Bayles KW: Acetic acid induces expression of the Staphylococcus aureus cidABC and $\operatorname{lrg} A B$ murein hydrolase regulator operons. J Bacterio/ 2005, 187(3):813-821.

29. Groicher KH, Firek BA, Fujimoto DF, Bayles KW: The Staphylococcus aureus $\operatorname{Irg} A B$ operon modulates murein hydrolase activity and penicillin tolerance. J Bacteriol 2000, 182(7):1794-1801.

30. Bayles KW: The biological role of death and lysis in biofilm development. Nat Rev Microbiol 2007, 5(9):721-726.

31. Wang IN, Smith DL, Young R: Holins: the protein clocks of bacteriophage infections. Annu Rev Microbiol 2000, 54:799-825.

32. Wang IN, Deaton J, Young R: Sizing the holin lesion with an endolysinbeta-galactosidase fusion. J Bacteriol 2003, 185(3):779-787.

33. Savva CG, Dewey JS, Deaton J, White RL, Struck DK, Holzenburg A, Young R: The holin of bacteriophage lambda forms rings with large diameter. $\mathrm{Mol}$ Microbiol 2008, 69(4):784-793.

34. White R, Chiba S, Pang T, Dewey JS, Savva CG, Holzenburg A, Pogliano K, Young R: Holin triggering in real time. Proc Natl Acad Sci U S A 2011, 108(2):798-803. 
35. Ranjit DK, Endres JL, Bayles KW: Staphylococcus aureus CidA and LrgA proteins exhibit holin-like properties. J Bacterio/ 2011, 193(10):2468-2476.

36. Bayles KW: Are the molecular strategies that control apoptosis conserved in bacteria? Trends Microbiol 2003, 11:306-311.

37. Ahn SJ, Rice KC, Oleas J, Bayles KW, Burne RA: The Streptococcus mutans Cid and Lrg systems modulate virulence traits in response to multiple environmental signals. Microbiology 2010, 156(Pt 10):3136-3147.

38. Sharma-Kuinkel BK, Mann EE, Ahn JS, Kuechenmeister LJ, Dunman PM, Bayles KW: The Staphylococcus aureus LytSR two-component regulatory system affects biofilm formation. J Bacterio/ 2009, 191(15):4767-4775.

39. Brunskill EW, Bayles KW: Identification of LytSR-regulated genes from Staphylococcus aureus. J Bacteriol 1996, 178(19):5810-5812.

40. Zhu T, Lou Q, Wu Y, Hu J, Yu F, Qu D: Impact of the Staphylococcus epidermidis LytSR two-component regulatory system on murein hydrolase activity, pyruvate utilization and global transcriptional profile. BMC Microbiol 2010, 10:287

41. Chandramohan L, Ahn JS, Weaver KE, Bayles KW: An overlap between the control of programmed cell death in Bacillus anthracis and sporulation. J Bacteriol 2009, 191(13):4103-4110.

42. Kobayashi K, Ogura M, Yamaguchi H, Yoshida K, Ogasawara N, Tanaka T, Fujita Y: Comprehensive DNA microarray analysis of Bacillus subtilis twocomponent regulatory systems. J Bacteriol 2001, 183(24):7365-7370.

43. Brunskill EW, Bayles KW: Identification and molecular characterization of a putative regulatory locus that affects autolysis in Staphylococcus aureus. J Bacteriol 1996, 178(3):611-618.

44. Patton TG, Yang SJ, Bayles KW: The role of proton motive force in expression of the Staphylococcus aureus cid and Irg operons. Mol Microbiol 2006, 59(5):1395-1404.

45. Wu C, Cichewicz R, Li Y, Liu J, Roe B, Ferretti J, Merritt J, Qi F: Genomic island TnSmu2 of Streptococcus mutans harbors a nonribosomal peptide synthetase-polyketide synthase gene cluster responsible for the biosynthesis of pigments involved in oxygen and $\mathrm{H}_{2} \mathrm{O}_{2}$ tolerance. Appl Environ Microbiol 2010, 76(17):5815-5826.

46. Merritt J, Qi F, Shi W: A unique nine-gene comY operon in Streptococcus mutans. Microbiology 2005, 151(Pt 1):157-166.

47. Petersen $F C$, Tao L, Scheie AA: DNA binding-uptake system: a link between cell-to-cell communication and biofilm formation. J Bacteriol 2005, 187(13):4392-4400

48. Dubbs JM, Mongkolsuk S: Peroxiredoxins in bacterial antioxidant defense. Subcell Biochem 2007, 44:143-193.

49. Horst SA, Jaeger T, Denkel LA, Rouf SF, Rhen M, Bange FC: Thiol peroxidase protects Salmonella enterica from hydrogen peroxide stress in vitro and facilitates intracellular growth. J Bacteriol 2010, 192(11):2929-2932.

50. Stourman NV, Branch MC, Schaab MR, Harp JM, Ladner JE, Armstrong RN: Structure and function of YghU, a nu-class glutathione transferase related to YfcG from Escherichia coli. Biochem 2011, 50(7):1274-1281.

51. Stohl EA, Seifert HS: Neisseria gonorrhoeae DNA recombination and repair enzymes protect against oxidative damage caused by hydrogen peroxide. J Bacterio/ 2006, 188(21):7645-7651.

52. LeBel CP, Ischiropoulos H, Bondy SC: Evaluation of the probe 2',7'dichlorofluorescin as an indicator of reactive oxygen species formation and oxidative stress. Chem Res Toxicol 1992, 5(2):227-231.

53. Jakubowski W, Bartosz G: 2,7-dichlorofluorescin oxidation and reactive oxygen species: what does it measure? Cell Biol Int 2000, 24(10):757-760.

54. Palazzolo-Ballance AM, Reniere ML, Braughton KR, Sturdevant DE, Otto M, Kreiswirth BN, Skaar EP, DeLeo FR: Neutrophil microbicides induce a pathogen survival response in community-associated methicillinresistant Staphylococcus aureus. J Immunol 2008, 180(1):500-509.

55. Cha MK, Kim HK, Kim IH: Mutation and Mutagenesis of thiol peroxidase of Escherichia coli and a new type of thiol peroxidase family. J Bacteriol 1996, 178(19):5610-5614

56. Ajdic D, McShan WM, McLaughlin RE, Savic G, Chang J, Carson MB, Primeaux C, Tian R, Kenton S, Jia $\mathrm{H}$, et al: Genome sequence of Streptococcus mutans UA159, a cariogenic dental pathogen. Proc Natl Acad Sci U S A 2002, 99(22):14434-14439.

57. Kreth J, Zhang $Y$, Herzberg MC: Streptococcal antagonism in oral biofilms: Streptococcus sanguinis and Streptococcus gordonii interference with Streptococcus mutans. J Bacteriol 2008, 190(13):4632-4640.
58. Itzek A, Zheng L, Chen Z, Merritt J, Kreth J: Hydrogen Peroxide-Dependent DNA Release and Transfer of Antibiotic Resistance Genes in Streptococcus gordonii. J Bacteriol 2011, 193(24):6912-6922.

59. Battig P, Muhlemann K: Influence of the spxB gene on competence in Streptococcus pneumoniae. J Bacterio/ 2008, 190(4):1184-1189.

60. Li YH, Lau PC, Lee JH, Ellen RP, Cvitkovitch DG: Natural genetic transformation of Streptococcus mutans growing in biofilms. J Bacteriol 2001, 183(3):897-908.

61. Aspiras MB, Ellen RP, Cvitkovitch DG: ComX activity of Streptococcus mutans growing in biofilms. FEMS Microbiol Lett 2004, 238(1):167-174.

62. Perry JA, Jones MB, Peterson SN, Cvitkovitch DG, Levesque CM: Peptide alarmone signalling triggers an auto-active bacteriocin necessary for genetic competence. Mol Microbiol 2009, 72(4):905-917.

63. Dufour D, Cordova M, Cvitkovitch DG, Levesque CM: Regulation of the competence pathway as a novel role associated with a streptococcal bacteriocin. J Bacteriol 2011, 193(23):6552-6559.

64. Grundy FJ, Waters DA, Allen SH, Henkin TM: Regulation of the Bacillus subtilis acetate kinase gene by CcpA. J Bacteriol 1993, 175(22):7348-7355.

65. Wolfe AJ: The acetate switch. Microbiol Mol Biol Rev 2005, 69(1):12-50.

66. Kim JN, Ahn SJ, Seaton K, Garrett S, Burne RA: Transcriptional Organization and Physiological Contributions of the relQ Operon of Streptococcus mutans. J Bacteriol 2012, 194(8):1968-1978.

67. Chen PM, Chen HC, Ho CT, Jung CJ, Lien HT, Chen JY, Chia JS: The twocomponent system ScnRK of Streptococcus mutans affects hydrogen peroxide resistance and murine macrophage killing. Microbes Infect 2008, 10(3):293-301

68. Deng DM, Liu MJ, ten Cate JM, Crielaard W: The VicRK system of Streptococcus mutans responds to oxidative stress. J Dent Res 2007, 86(7):606-610.

69. Wen ZT, Suntharaligham P, Cvitkovitch DG, Burne RA: Trigger factor in Streptococcus mutans is involved in stress tolerance, competence development, and biofilm formation. Infect Immun 2005, 73(1):219-225.

70. Wen ZT, Baker HV, Burne RA: Influence of BrpA on critical virulence attributes of Streptococcus mutans. J Bacteriol 2006, 188(8):2983-2992.

71. Wen ZT, Burne RA: LuxS-mediated signaling in Streptococcus mutans is involved in regulation of acid and oxidative stress tolerance and biofilm formation. J Bacterio/ 2004, 186(9):2682-2691.

72. Baldeck JD, Marquis RE: Targets for hydrogen-peroxide-induced damage to suspension and biofilm cells of Streptococcus mutans. Can J Microbiol 2008, 54(10):868-875.

73. Cheung J, Hendrickson WA: Sensor domains of two-component regulatory systems. Curr Opin Microbiol 2010, 13(2):116-123.

74. Cho HY, Cho HJ, Kim YM, Oh Jl, Kang BS: Structural insight into the hemebased redox sensing by DosS from Mycobacterium tuberculosis. J Biol Chem 2009, 284(19):13057-13067.

75. Podust LM, loanoviciu A, de Montellano PR O: 2.3 A X-ray structure of the heme-bound GAF domain of sensory histidine kinase DosT of Mycobacterium tuberculosis. Biochem 2008, 47(47):12523-12531.

76. Patton TG, Rice KC, Foster MK, Bayles KW: The Staphylococcus aureus cidC gene encodes a pyruvate oxidase that affects acetate metabolism and cell death in stationary phase. Mol Microbio/ 2005, 56(6):1664-1674.

77. Ahn SJ, Lemos JA, Burne RA: Role of HtrA in growth and competence of Streptococcus mutans UA159. J Bacteriol 2005, 187(9):3028-3038.

78. Abranches J, Candella MM, Wen ZT, Baker HV, Burne RA: Different roles of ElIABMan and EllGlc in regulation of energy metabolism, biofilm development, and competence in Streptococcus mutans. J Bacteriol 2006 188(11):3748-3756

79. Ahn SJ, Wen ZT, Burne RA: Multilevel control of competence development and stress tolerance in Streptococcus mutans UA159. Infect Immun 2006, 74(3):1631-1642.

80. Yin JL, Shackel NA, Zekry A, McGuinness PH, Richards C, Putten KV, McCaughan GW, Eris JM, Bishop GA: Real-time reverse transcriptasepolymerase chain reaction (RT-PCR) for measurement of cytokine and growth factor mRNA expression with fluorogenic probes or SYBR Green I. Immunol Cell Biol 2001, 79(3):213-221.

81. Edgar R, Domrachev M, Lash AE: Gene Expression Omnibus: NCBI gene expression and hybridization array data repository. Nucleic Acids Res 2002, 30(1):207-210.

82. Brazma A, Hingamp P, Quackenbush J, Sherlock G, Spellman P, Stoeckert C, Aach J, Ansorge W, Ball CA, Causton HC, et al: Minimum information about a microarray experiment (MIAME)-toward standards for microarray data. Nat Genet 2001, 29(4):365-371. 
83. Seaton $\mathrm{K}$, Ahn SJ, Sagstetter AM, Burne RA: A transcriptional regulator and $A B C$ transporters link stress tolerance, (p)ppGpp, and genetic competence in Streptococcus mutans. J Bacteriol 2011, 193(4):862-874.

84. Trieu-Cuot P, Carlier C, Poyart-Salmeron C, Courvalin P: A pair of mobilizable shuttle vectors conferring resistance to spectinomycin for molecular cloning in Escherichia coli and in gram-positive bacteria. Nucleic Acids Res 1990, 18(14):4296.

85. Que YA, Haefliger JA, Francioli P, Moreillon P: Expression of Staphylococcus aureus clumping factor $\mathrm{A}$ in Lactococcus lactis subsp. cremoris using a new shuttle vector. Infect Immun 2000, 68(6):3516-3522.

doi:10.1186/1471-2180-12-187

Cite this article as: Ahn et al:: Identification of the Streptococcus mutans LytST two-component regulon reveals its contribution to oxidative stress tolerance. BMC Microbiology 2012 12:187.

\section{Submit your next manuscript to BioMed Central and take full advantage of:}

- Convenient online submission

- Thorough peer review

- No space constraints or color figure charges

- Immediate publication on acceptance

- Inclusion in PubMed, CAS, Scopus and Google Scholar

- Research which is freely available for redistribution 